Summer 2021

\title{
A New Manifestation of American Socially Engaged Fiction
}

\author{
Magdalena Bazylewicz
}

\section{(2) OpenEdition \\ 1 Journals}

Electronic version

URL: https://journals.openedition.org/ejas/17170

DOI: 10.4000/ejas. 17170

ISSN: 1991-9336

\section{Publisher}

European Association for American Studies

\section{Electronic reference}

Magdalena Bazylewicz, "A New Manifestation of American Socially Engaged Fiction ", European journal of American studies [Online], 16-2 | 2021, Online since 14 July 2021, connection on 17 October 2022. URL: http://journals.openedition.org/ejas/17170 ; DOI: https://doi.org/10.4000/ejas. 17170

This text was automatically generated on 17 October 2022

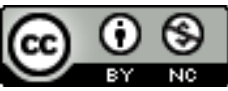

Creative Commons - Attribution-NonCommercial 4.0 International - CC BY-NC 4.0

https://creativecommons.org/licenses/by-nc/4.0/ 


\title{
A New Manifestation of American Socially Engaged Fiction
}

\author{
Magdalena Bazylewicz
}

In 2000, author Barbara Kingsolver proposed granting an award for socially engaged fiction to authors of unpublished manuscripts. As of 2020, ten manuscripts have been awarded and published. The PEN/Bellwether Prize for Socially Engaged Fiction is awarded biannually to writers pursuing their novelistic debut through literary work that meets the competition criteria of socially engaged fiction, which, according to the official award website

\begin{abstract}
may describe categorical human transgressions in a way that compels readers to examine their own prejudices [or] invoke the necessity for economic and social justice for a particular ethnic or social group, or it may explicitly examine movements that have brought positive social change. Or, it may advocate the preservation of nature by describing and defining accountable relationships between people and their environment. The mere description of an injustice, or of the personal predicament of an exploited person, without any clear position of social analysis invoked by the writer, does not in itself constitute socially engaged literature. "Social engagement" describes a moral obligation of individuals to engage with their communities in ways that promote a more respectful coexistence, to question and confront, to work towards betterment. (PEN//Bellwether Prize for Socially Engaged Fiction, par. 6)
\end{abstract}

2 The present paper aims to examine how and if a winning novel fulfills the ambitious task set by the jury. Moreover, I am going to demonstrate that tools provided by New Historicism, a theory at whose "center (...) lies a claim (...) that literature does political work" (Holstun 190), can be used to evaluate social engagement, i.e. to examine the social and political dimension of a text of culture through discourse analysis and exploring the relation between public and private. That notion has been rejuvenated through the work of Anis Shivani, mainly his essay "We are All Neoliberals Now: The New Genre of Plastic Realism in American Fiction." The essay, embedded in the wider context of New Historicism, constitutes a work relevant while considering the winner of the Bellwether Prize. Shivani distinctly sees literature as political and positions the political and social engagement of the novel on the axis of the public and the private. 
That distinction poses a concern for New Historicist scholars examining the ideas of Jameson and Lyotard as they both extensively discussed political dimensions of texts of culture. Jameson explores the distinction between social and political texts and those which are not considered political, and finds that such separation "between history or society and the 'individual' maims our existence as individual subjects and paralyzes our thinking about time and change just as surely as it alienates us from our speech" (The Political Unconscious 2). Every text of culture shall be treated as political in an attempt to expose the forces that shape it. In turn, Lyotard pronounces that capitalism is a source not of privatization, but of false integration, or monological totalization, that is "a single language and a single network" (Greenblatt 4). In the chosen novel, the monological totalization takes the form of a pervasive use of new media-based social and political discourse, which remains unexamined and becomes the reality of the chosen novel, which shall be illustrated in the second part of the paper. Secondly, Shivani's analysis of discourse as a tool of propagating ideology strongly echoes Foucauldian discourse analysis adopted by New Historicist scholars. Through the analysis of discourse in And West is West the article shall determine if and to what degree discourse examines itself and the reality of the novel enabling the characters to meaningfully engage in the constructed public reality, i.e. reality which is a negotiation and power struggle between discourses (media, public authorities, business, private conversations etc.), in which they are enmeshed. In other words, the discourse analysis makes it possible to demonstrate the depth of the social argument conveyed by the novel.

3 Having applied the above criteria to American fiction, Shivani arrives at a bitter conclusion: it is a tool of market economy used to tranquilize its consumer, obfuscate sources of resistance and eradicate a dangerous sense of community (Shivani, "We are all..." pars. 14, 18). Shivani claims that contemporary American fiction is subservient to and propaganda for neoliberal ideology, which manifests through a dominant literary trend he calls plastic realism. ${ }^{1}$ The label encompasses various literary tools revered contemporary authors use to perpetuate neoliberal "ethic of unlimited individual responsibility" (par 15). These include therapeutic narrative [which] ensures that individuals can only grow and learn from such experiences (...) a subject that fully conforms to the ideals of the neoliberal economy, [whose] all problems originate internally (par. 18). He expands on this in "The Shrinking of American Fiction":

in the vast majority of novels, it seems now that accidents, catastrophic illness (...) mental illness, acts of nature (it used to be God), in short, events beyond the control of ordinary mortals (...) determine the very shape and structure of the narrative. The characters, despite being trendy cosmopolitan types, are acted upon rather than acting (...). Something beyond their control happens to an individual which takes them on a therapeutic journey through a landscape of comfortable cultural signs forming the background for internal epiphany leading them to conclusions that one expects in a therapist's office. (683-685)

4 The ultimate goal of the characters becomes to achieve private fulfillment. Public problems are merely obstacles on the path to personal enlightenment. The narrative is not concerned with the origin of those struggles and with forces that push the individual to do what they do, think how they think, speak how they speak and (not) question the order of things. The struggle against the obstacles is a therapeutic process of the individual. Esteemed texts, just as neoliberal economy, refuse to acknowledge the workings of power-knowledge and how the individual is caught between discourses 
whose origin is not questioned; rather, the discourses intertwining is treated as the natural order of things.

Shivani's main concern lies with the way the narrative works toward a topography where the characters are disconnected from the community. Their private development is the true hero of the plot. He hints at how the unified, totalized discourse contributes to that notion: "The explanation of political events-9/11 and its aftermath, for instance, or since then the economic collapse-is a given, taken directly from official media; one enters this landscape already knowing the beginning and end of the political game, though characters may spend some time in the playground of emotions" ("We are all...", par 75). That is what we shall see in the analysis of the novel, where the outcome of character's journey is foreshadowed by a discourse used to create the political and social landscape of the novel.

\section{And West is West, and the gospel of individuality}

6 Ron Childress' And West is West is the author's only novel. The manuscript won the PEN/ Bellwether Prize for Socially Engaged Fiction in 2014. In 2015 the novel was published by Algonquin Books. It received sparse but favorable reviews which consistently identify the theme of the novel as the consequences of technology detaching people from the results of their actions, ${ }^{2}$ a conclusion in line with an assertion of the author: "My intention became to show how our lives had become interconnected by the then new technologies, and particularly how those connections can be abused - how the distancing that technology allows makes it easier for people to behave as if they aren't responsible for their behavior" (Childress, "And west is..."). The premise of social engagement as defined by the award seems to be fulfilled - the "as if" in Childress' utterance exhibits disapproval of individuals distancing themselves and their actions from the impact they have on their environment. The novel aims to highlight that condition, therefore appealing to readers interested in works embracing the relationship between the private and the social.

7 The realm of public and the realm of private interweaving constitutes the fictional premise of the novel. Plotlines of two main characters, Ethan and Jessica are developed separately for the better part of the novel to ultimately converge and reveal convergence points deep in their past. Ethan works in a bank and writes algorithms, which facilitate profiting from calamities, such as terrorist incidents. Jessica is a military drone operator. When Jessica launches a strike on alleged foreign terrorist target, Ethan's code reacts to the incident and makes money for the bank and its clients. Two main characters constitute a frame for the military-industrial complex. The third prominent character is Zoe, Ethan's ex-girlfriend, a disoriented young woman whose eventual death plays a major part in Ethan's transformation.

The character arc of the main characters is exemplary of what Shivani calls the "ethics of unlimited individual responsibility" ("We are all...", par. 15). The ultimate goal and result of their actions is to experience an epiphany and undergo a change in order to save themselves. Ethan begins as a person moderately aware of the nefarious nature of the machine, which employs him. "Ethan puts in eighteen-hour days working on (...) a modification to UIB currency trading algorithm, which currently monitors volatility in relation to news reports of terrorist activity; (...) he binges on coffee and Provigil to keep alert" (Childress 13). A perfunctory allusion to the 2008 financial crisis, using two 
financial terms which became buzzwords at the time, is made to sketch his position and attitude: "Ethan's bank, United Imperial Bank, had contributed its share of shaky credit default swaps and collateralized debt obligations, but all this was outside his division" (18). His responsibility is obfuscated by his general sincerity and hard-working attitude to the point of harming his own health, which signalizes a certain naiveté and may absolve him of true responsibility. The focus is drawn to Ethan's private life - his developing relationship with Zoe and his hip friends. Devoid of any previous analysis, an isolated, matter-of-fact statement-- "Wars don't happen every day and he's responsible for capitalizing on them" (64)-- is separate from Ethan and deliberately excessive so as to foreshadow personal change he is about to undergo.

Early in the novel Ethan offers no critical thought about his role in the system. The only time the issue is mentioned it is through Zoe's father, who bitterly comments on Ethan's professional career: "You just enable them (...) Those banking sons-a-bitches that wrecked my portfolio, the economy, a hundred million Americans' retirement, what have you;" however Ethan remains unfazed: "Leston is blaming him for steering the Titanic into an iceberg when he was only manning the ship's telegraph" (18). He dismisses the remark and the matter is not examined in any way until his single thought on war profiteering. His life unravels after he isfired for allegedly making a mistake in the code. His professional downfall is tied to the aftermath of the 2008 economic crisis. Once he makes a costly "decimal point mistake" (99) in the code, he is fired from the bank. Upon realizing that his lavish lifestyle is about to end, he immediately diagnoses the inherent injustice of the system:

After Lehman blew up in ' 08 and the world nearly followed, UIB tossed a bone to the Fed by tying employee bonuses to long-term performance. (...) Of course UIB executives and stars were exempt from the clause. (...) Ethan is about to lose (...) everything. His six-figure bank account. His retirement investments. His platinum credit limit. Perhaps even his condo. In the previous century the sin of losing money was forgivable. Bankruptcy was lenient. The rich were neither so rich nor so greedy nor so paranoid. But with the American century shrinking in the rearview mirror, the country has given up on being the land of second chances, or even first. (100)

Ethan's change is marked by platitudes. Nowhere in the novel is there an explanation of Ethan arriving at such broad conclusions in a logical and coherent manner. Such a sudden shift from personal loss to high-principled criticism of the system appears artificial. It might be construed as a critique of Ethan's thoughtless, disjointed leap from his personal disappointment to public criticism and therefore, a critique of a perspective, which reaffirms the system. The system is able to operate because of such a disjointed, unreflective attitude - in an instant Ethan does not see himself as a part of the system but as a victim separate from the workings of the system. When the system does not let him prosper he assumes the position of the victim, which in turn means that to his mind, as long as the system allows him to thrive, he is indifferent to its nefarious working. The system essentially becomes invisible. However, there is no other evidence to support such interpretation. The narrative does not call any attention to Ethan's sudden pivot from his personal disappointment to public criticism. Ethan's newfound indignation lacks footing in any preceding thought process, therefore at this point is nothing more than a manifestation of resentment after a personal loss. Furthermore, the novel attempts to authenticate his change - the plot takes Ethan through a chain of events of significant emotional burden from which 
he is to emerge reawakened. By all evidence in the novel, his change is genuine and admirable.

Zoe, a secondary character, works as a prop facilitating Ethan's journey. Zoe Leston represents an ultimately passive character. The character is positioned to be antithetic to Ethan's - she is a soul-searching activist ("This could be naive but I still dream the world might be a better place if I help" (24)), who is prey to the system that Ethan helps build. Her father, "deep in the stock market, had disastrously cashed out in '08. (...) He has bequeathed Zoe nothing but debt" (91). Zoe's mother, who suffers from Alzheimer's disease, and her father, who has been diagnosed with pancreatic cancer, commit suicide. Prior to the incident, Zoe's father contacts Ethan, Zoe's ex-partner and gives him documents which reveal that the people who Zoe considers to be her parents are in fact her grandparents, as her mother died in a car crash during Zoe's infancy. Ethan withholds the documents for a while, unable to deal with the situation. Once Zoe learns about her background, she begins to unravel, and follows the path of exhausting soulsearching, which ultimately results in her death. Whether her death is an accident or suicide remains unknown. Ethan becomes preoccupied with the nature of her death and his own culpability. Zoe is Ethan's pang of conscience; her character is emphatically created to strike a private, emotional note in Ethan. His pursuit for explanation and meaning in Zoe's life and death advances his plotline: he learns about Zoe's real father and her half-sister, Jessica. Driven by guilt and regret, he decides to help Jessica escape the authorities: "He can save Jessica. He will. This time and from now on, he will do the right thing" (286). He then withdraws from a lucrative yet suspicious financial opportunity and becomes a teacher. Ethan's character arc is explicitly summarized at the end of the novel in a letter from Jessica's father: "There would have been no Zoe and you and me would have never met (...) You [would be] probably still at your bank and not sick over what you do. (...) Is that what Zoe's death was about? Making you a more decent man? It got to have some meaning" (302). The quote constitutes the true premise of the novel. The ultimate objective of the characters is to reach personal realization and moral purification. The system, while inherently corrupt and hostile to true humanity is there to help the characters achieve that understanding. The premise unwittingly fulfills the main assumption of Shivani's "plastic realism [which] offers sacred reassurance that the world is not actually threatening or hostile (despite disconcerting events like $9 / 11$ or the Iraq war or the economic collapse), that suffering and loss (and even death) have an ultimate meaning that can be transparently psychologized and understood (...) the therapeutic narrative ensures that individuals can only grow and learn from such experiences" ( "We are all...", par. 25). It is the moral growth of the individual character that constitutes the true theme and argument of the novel.

12 Another main character, Jessica Aldridge is a military drone operator responsible for striking overseas targets. She is introduced as she is indulging in a romantic fantasy while watching a target she is about to strike with a drone: "...she imagines one of the young men in jalabiyas looking up at the shooting star that cuts through the night sky at a strange angle. He will shout a warning in the twenty seconds that remain. Everyone will scatter. Even the invisible man in the SUV will dive out and roll to safety. In her fantasy all this occurs" (Childress 3). In pursuit of a Yemeni terrorist, she launches an attack on a vehicle, which is allegedly transporting the terrorist. Right before she fires, she notices two young boys emerging from the vehicle; however, intimidated by her 
commander, she launches the missile, killing the children. Guilt-ridden, she shares the experience in a letter to her imprisoned father. The authorities deem her a liability, and Jessica flees the military, intending to remain off the grid. Pursued by the FBI, she aimlessly wanders around and experiences emotional distress at losing the life she once knew. Her story becomes one of a noble soldier trying to escape the corrupt power of the state represented by two FBI agents. Ultimately, exhausted and feeling trapped, she reports to the authorities. Due to certain new information, her name is cleared. However, she permanently leaves the Air Force and starts working for a private contractor monitoring the U.S - Mexican border for cartel activity. She uses the surveillance system to find and help illegal immigrants before they are caught by the border patrols.

Similarly to Ethan's character arc, Jessica's objective is to disengage and save herself. She is stripped of personal responsibility by apparently being oblivious to the consequences of her actions: "Not until dawn will anyone completely see what Jessica has done. She never will. Strike analysis is above her security classification" (3); "covert snacking is the main pastime during shifts at a drone monitor; (...) They wait; (...) There is no scenery, only images on monitors; (...) She's just pulling a switch" (28). At the same time she understands these consequences enough to feel guilty: "Jessica knows how the silent guilt builds. You learn to deal with it or crack. In other words, you smoke. Maybe, she thinks, risking their lungs is some atonement for being beyond the line of fire. God bless Philip Morris" (30). In the light of her position in the chain of command and emotional response to the botched drone strike, Jessica's guilt is both unsubstantiated and trivialized through self-punishing smoking ritual. Her guilt is merely proof of her righteousness. Between joining the AirForce to escape a troubled family, being reduced to a cog in the military industry and Philip Morris, a corporation profiting off her addiction, Jessica is a victim. Both she and Ethan are not truly corrupt. They have always retained their individuality and being a part of the system is their moment of weakness, for which they both pay a seemingly disproportionate price. The objective of their journey throughout the novel is to fully reclaim that individuality.

The journey to reclaim individuality is represented in both characters through their transformation of appearance. Jessica takes off her uniform and all that comes with it: "She's not a protector anymore, a self-conception on which her self-esteem has depended" (53). She removes a symbolic eagle tattoo: "She will keep on the move for the same reason she is undoing her tattoo (...) to be no longer what she was" (75). She rids her body of a foreign element attaching her to the public sphere in the attempt to save herself by becoming private again. Ethan sheds the suit and begins wearing "gray fleece top and faded jeans" (115), and loses weight. With the changed appearance comes a revelation about his professional pursuits: "if he's to go after a job like his old one, he will have to hold his nose and man up again. Maybe this, he thinks, is what's caused him to delay his job search. Disgust" (113). The parallel between returning to a more comfortable physical state and more honest moral state signifies the return to Ethan's true, private self, the one that is authentic and good.

Lastly, the guilt transforms into a private matter of upholding personal standards: "She tries to smile at the streaked mirror, but the mirror grimaces back. Here is someone who has let down her family, her country, everything and everyone who relied on her" (273). This statement resembles Ethan's abovementioned summary of the financial system as it is detached from any previous factual, emotional or analytical work 
performed by the character. Ethan only acknowledges that he was a part of a war profiteering scheme once he loses his place within that scheme; "he feels like a hatchling ejected from the nest" (100). Jessica is shaken by the fact that her failed strike resulted in casualties, but it matters only as her private trauma. We see it take a toll on her body, mental state and subsequent torment she experiences while on the run from authorities. In both cases of Ethan and Jessica the role they played in the system is forgotten and the foundations and critique of the system is not analyzed further; we are presented only with the private, personal consequences of the characters' mistakes and the resulting private distress which serves as their path to atonement.

Despite going in opposite directions, Ethan and Jessica's reasoning results in disconnecting the realms of public and private. Ethan abruptly translates his own private experience into a diagnosis of the system in order to find redemption in breaking with the system. Jessica translates the workings of the system into her private guilt. In both cases the two spheres must be disconnected in order to redeem the characters. Personal redemption is the only thing that matters; it is particularly visible in Jessica's choice to surrender to the authorities. By surrendering, she uses the military as a tool to receive personal redemption, regardless of any public good that may come from doing otherwise.

17 For both main characters, the initial circumstances of their lives and subsequent lifealtering decisions pushing their individual plots forward, are triggered by personal conflicts and desires, mostly pragmatic and fueled by self-serving interest. Their epiphanies are not a result of close examination of the workings of the system but of personal failures, which made them no longer desired by the entities which they had been serving, and subsequent uprooting of their lives. Their apparent rebellion against the system is a consequence of their becoming liabilities. The system posits obstacles for them to overcome in order to arrive at their own, private understanding of their priorities and ethic. This is what makes the novel and example of what Shivani calls "plastic realism" - a work which ultimately proves that a meaningful transformative action upon the system is virtually impossible and where "geographies (...) emerge as embodiments of diffuse power, against which the individual has little hope of making his or her presence felt" ( "We are all...", par. 75). Hence, the only thing one is able to do is to disengage and sever the links between the individual and the state. This way the system corrects itself and pushes both characters to pursue meaningful lives outside of it. The novel ultimately realizes what Shivani calls the neoliberal virtue of personal responsibility. On the face of it, the novel sets out to criticize the workings of the corrupt system, but in effect it elevates a position of disengagement of the individual, which allows the system to thrive unchallenged, thus, reinforcing its hegemony.

18 In addition to character arcs communicating personal elevation, another crucial aspect of plastic realism as described by Shivani recurs: a media-derived discourse constructing the realm of the novel. In Shivani's thought, what is supposed to ground the reader in reality is to present the reader "in the mirror of popular culture, (...) [through writing] derivative and dependent on popular culture [through] the proliferation of product labels to indicate, quickly and cheaply, what we are to take as the foundations of character [and] plots are directly borrowed from mass media" (681- 
684). In And West is West this is manifested through a profuse use of buzzwords and perfunctory references to social and political phenomena.

The reality of the characters is woven from elements of mass media phraseology. Buzzwords and buzz phrases signal the social and political context and bias of the characters as well as of the novel in its entirety. They are present in the utterances of the characters, and they are embedded in the third person narration mode.

To decipher them the reader has to refer to texts and contexts outside of the novel. As it shall be demonstrated later, these buzz phrases construct a scaffolding upon which the major character arc is suspended. Buzzwords are used gratuitously and in isolation from the socio-political consciousness of the novel. Their origin and cultural connotations are never explained. Outside the novel, buzz words arise at the intersection of pop culture, old and new media, politics and social issues, which the novel never acknowledges; they are separate from the novel's disinterest in the everyday socio-political reality of the characters. Here are some examples: a woman in the prison that Ethan visits calls her son "Barack Hussein" (275). The use of Barack Obama's middle name became a talking point in the media during the 2008 presidential campaign. Conservative media representatives insisted on using the full name, which the liberal pundits dismissed as racist and manipulative. The controversy over a trivial subject proved attractive and made its way to the 80th Academy Awards monologue, when the host Jon Stewart referenced the issue: "His middle name is the last name of Iraq's former tyrant. (...) That's not easy to overcome. (...) I think we all remember the ill fated 1944 presidential campaign of Gaydolf Titler" (qtd in Holden). In the context, the woman in the novel acknowledges the right-wing crude attempt to subvert Obama's authority and positions herself as his staunch supporter.

21 In another instance, a hint of criticism of the apparent hypocrisy of political correctness is visible in the following passage: "Zoe and Mariatu Nowrojee are enjoying lunch on an unseasonably warm day that in a former age might have been called Indian. But use the term Indian summer in this town and you will get your hand slapped. At the same time you can root loudly for the Redskins" (Childress 103). The Washington Redskins' name controversy has been widely publicized in popular media outlets, not only sports-related but also featured in cartoons (South Park), popular comedy shows (Last Week Tonight with John Oliver, The Daily Show), and numerous social media personalities with a wide audience (Joe Rogan, Bill Burr). The issue of politically correct language is not acknowledged anywhere else in the novel.

The buzzword imagery is not limited to single words and phrases, but extends to certain cursorily treated concepts, which serve as building blocks of the mindset of the character. An isolated remark is made towards modern art: "After all, what's really big in art seems to be giant puppies made of flowers or great white sharks embalmed in vitrines, and these don't appeal to Ethan" (298). The excerpt references Puppy, a statue of a dog made of flowers by artist Jeff Koons in 1997, and The Physical Impossibility of Death in the Mind of Someone Living, an iconic piece by a British artist Damien Hirst created in 1991. Both pieces are fairly dated and have generated enough commentary in the media to be easily recognizable by the general public. To invoke them is to bring up the straightforward, unpretentious sentiment to add to the naivete of the character and to further absolve him of participating in a corrupt scheme. Ethan does not share the suspicious, avant-garde tastes associated with the elites, which further distances him from fully understanding the business establishment and its sins. 
23 In a drunken e-mail to Zoe, Ethan explains how he potentially wrecked a job opportunity because he called a Russian billionaire an "oilagarch" (170). There is no further commentary clarifying this neologism. It conveys a vague idea of corruption and ruthless war over resources. To use such a hackneyed notion might work as criticism of perfunctory knowledge manifested through gratuitous use of buzzwords without deeper understanding of matters behind them; however, the novel lacks any evidence that could point the reader toward such interpretation. The reader is supposed to sympathize with Ethan's character and assume that his point of view is the correct one. After all, he has become a victim of the bank, which ultimately equates to him being no longer oblivious to its corrupt nature.

Another clear example is the term too-big-to-fail, used by the character of Alex, Ethan's best friend: "You'd think he was CIA planning a hit on the next Osama bin Laden. But he just crunches data for one of those too-big-to-fail banks" (9). The term "too-big-tofail" emerged as a buzzword in the aftermath of the 2008 financial crisis. It has been continuously used by politicians, financial experts and media pundits, and it has thoroughly permeated pop culture. The phrase is inherently negative, evoking the image of tentacles of financial behemoths reaching so deeply into the fabric of society that they are impossible to eliminate without ripping everything apart. It suggests powerlessness in the face of the system. Another utterance exemplary of this kind of satirical, superficial interpretation is Alex's comment on Zoe's and Ethan's possible offspring destined for dominance: "What a match you two'd make. The banker and the politician. Your kids'll definitely grow up to be or overlords" (9).

The buzzwords, buzz phrases and buzz imagery colonize the minds of the characters. However, such ample use of these tools does not subvert or expose the hegemony of the mass media. Their origin is never questioned. Their connotations are never analyzed. They serve merely as flat references, which facilitate the positioning of the characters on a socio-political axis so as to make them more relatable to a reader whose mindset has been colonized by the same imagery. The imagery evokes the idea of a rigged, unjust system of discrimination and privilege; however by failing to analyze the origin and context of said imagery it reinforces the notion of an impenetrable system. Buzzwords reduce the reality to a witticism, often hyperbolized and flattened where there seem to be no cracks through which an individual could penetrate the system and eventually attempt to change it at a local level. They contribute to a general sense of incapability whose logical consequence for an individual might be not activism but resignation and withdrawal.

26 The lives of the characters are broken because of their voluntary entanglement in specific segments of the system which they intended to exploit. The portrayal of these segments, derivative of popular mass media imagery does not attempt to explain the inner workings, motivations or social consequences of the said segments, but renders it intangible as it is already filtered through image and media based associations.

And West is West, examined through the lens of Anis Shivani's criticism proves to assert a notion contrary to the assumption of socially engaged fiction as stated in the requirements of the competition, one of a "moral obligation of individuals to engage with their communities" (PEN/Bellwether). Through employment of discourse reliant on new media-derived buzzwords the novel places its characters in reality of unexamined socio-political media bias. Unexamined use of buzzwords dismisses the 
role of various factors responsible for creating and perpetuating the use of such expressions. The discourse appears natural, and thus, unlikely to be disputed.

Moreover, through the character arc, whose objective is to advance the individual moral development of the character while disconnecting from immoral parts of the system and community, the novel reinforces the system it appears to criticize. Individuals gain a conviction that their involvement with the hegemonic system is a private mistake that must be corrected to achieve personal satisfaction and peace. It is not the inherently corrupt system that needs intervention but their own engagement and attitude towards it. The characters withdraw into their private realm and abandon the public, leaving the system uncontested and allowing it to flourish.

\section{BIBLIOGRAPHY}

Childress, Ron. And West Is West. Algonquin Books of Chapel Hill, 2016.

Childress, Ron. “Re: And West is West.” Received by Magdalena Bazylewicz, 9 May, 2018.

Fry, Naomi. “Debut Novels.” The New York Times, 9 Oct. 2015, www.nytimes.com/2015/10/11/ books/review/debut-novels.html.

Greenblatt, Stephen. “Towards a Poetics of Culture.” The New Historicism, edited by H. Aram Veeser. Routledge, 1989. 1-14.

Holden, Jeremy. "Pot, Kettle: Matthews Criticizes Jon Stewart for Doing What He Did First and Continues Doing." Media Matters for America, 28 Feb. 2008, www.mediamatters.org/msnbc/potkettle-matthews-criticizes-jon-stewart-doing-what-he-did-first-and-continues-doing.

Holstun, James. "Ranting at the New Historicism." English Literary Renaissance, vol. 19, no. 2, 1989, JSTOR, www.jstor.org/stable/43447275. Accessed 1 May 2020.

Jameson, Fredric. Signatures of the Visible. New York-London: Routledge. 2007 [1992].

--- The Political Unconscious: Narrative as a Socially Symbolic Act. London: Routledge, 1989.

Memmott, Carol. “'And West Is West' Review: An Air Force Drone Pilot Hesitates to Fire.” The Washington Post, WP Company, 13 Oct. 2015, www.washingtonpost.com/entertainment/books/ and-west-is-west-review-an-air-force-drone-pilot-hesitates-to-fire/2015/10/13/ e6c78e5a-71c9-11e5-9cbb-790369643cf9_story.html.

“PEN/Bellwether Prize for Socially Engaged Fiction (\$25,000)." PEN America, 27 Feb. 2019, pen.org/literary-award/penbellwether-prize-for-socially-engaged-fiction-25000.

Shivani, Anis. “The Shrinking of American Fiction.” The Antioch Review, vol. 62, no. 4, 2004, p. 680. JSTOR, www.jstor.org/stable/4614734. Accessed 1 January 2020.

--- "We Are All Neoliberals Now: The New Genre of Plastic Realism in American Fiction." HuffPost, HuffPost, 12 June 2016, www.huffpost.com/entry/we-are-all-neoliberals-no_b_7546606. Accessed November 2019. 


\section{NOTES}

1. Other terms Shivani uses include neoliberal realism, market realism, commodified realism, mechanical realism, synthetic realism, textual realism, structured realism, formalized realism, anti-realism, pop realism, postmodern realism, fantastic realism, paranoid realism, sentimental realism, regressive realism, pedantic realism, and institutional realism ("We are all...", par 2).

2. Examples of reviews highlighting the aspects of detachment include: "a master study in how people can emotionally detach themselves from the damage they cause in our computer-driven world' (Memmott, par 7); "the book means to show us what happens to the individual when the stakes of personal responsibility are simultaneously heightened to their breaking point and reduced to mechanized functions" (Fry, par 3).

\section{ABSTRACTS}

The article addresses a peculiar manifestation of the contemporary American socially engaged novel: the PEN/Bellwether Prize for Socially Engaged Fiction. Using the tools of the New Historicism, the work scrutinizes Ron Childress' award-winning novel And West is West in an attempt to establish what it means for a modern work fiction to be socially engaged. Through creative application of Foucault's discourse analysis intertwined with AnisShivani's theory of plastic realism, the paper analyses the cultural forces at play in a self-proclaimed novel of social reform.

INDEX

Keywords: Ron Childress, American literature, socially engaged fiction, New Historicism 